\title{
Entrevista: A identidade de marca no desenvolvimento da marca de moda feminina FARM
}

\section{Interview: The brand identity in the development of women's fashion brand FARM}

\author{
Gabriela Costa Oliva \\ Mestranda em Design do Vestuário e Moda pela Universidade do Estado de Santa Catarina (Udesc) - \\ gaboliva@gmail.com - http://orcid.org/0000-0002-4902-5335 \\ Icléia Silveira \\ Doutora em Design pela Pontífice Universidade Católica do Rio de Janeiro (PUC/RIO). Professora da Universidade do \\ Estado de Santa Catarina (Udesc) - icleiasilveira@gmail.com - http://orcid.org/0000-0003-4493-9768
}

\section{Resumo}

Esta é uma entrevista com o bacharel em comunicação, professor e gerente de branding da marca de moda feminina FARM, Carlos Mach, realizada no dia 4 de outubro de 2017, por e-mail. É parte de uma pesquisa para o desenvolvimento de um estudo de caso sobre a marca onde atua. Durante a entrevista o profissional conta sobre sua trajetória profissional, suas experiências e de como chegou até a FARM. Mach relata como funciona seu trabalho com a marca em constante ascensão e de que forma a empresa iniciou o trabalho de branding. Exemplifica algumas das metodologias de trabalho desenvolvidas dentro da empresa e seus pensamentos sobre a importância da comunicação interna na FARM, do desenvolvimento integrado entre departamentos, da identidade para a marca, o contexto em que esta se encontra, seus valores, evolução e os planos para o futuro.

Palavras-chave: Branding. Marcas de moda. Estilo de vida. Entrevista.

\begin{abstract}
This is an interview with the communication bachelor, professor and branding manager at the women's fashion brand FARM, Carlos Mach. Held on October 4, 2017, by e-mail. It is a part of a research for the development of a case study about the brand where he operates. During the interview the professional tells a little about his professional career, his experiences and how he got into the brand FARM. Mach also tells how his work with the constantly growing brand works and how the company started its branding work. Exemplifies some of the work methodologies he has developed within the company and his thoughts on the importance of the FARM's internal communication, of the integrated development between departments, of the fashion brand identity, the context in which the brand is at the moment, its values, evolution and plans for the future.
\end{abstract}

Keywords: Branding. Fashion brands. Lifestyle. Interview. 


\section{APRESENTAÇÃO}

O comunicador, professor e gerente de branding Carlos Mach é formado pela Faculdades Integradas Hélio Alonso (FACHA), atua profissionalmente como gerente de branding da marca de moda feminina FARM desde 2004 e é professor de cursos de extensão em branding em instituições de ensino do sudeste do país, como o Instituto Rio Moda (Rio de Janeiro) e Perestroika (São Paulo).

Figura 1 - Carlos Mach

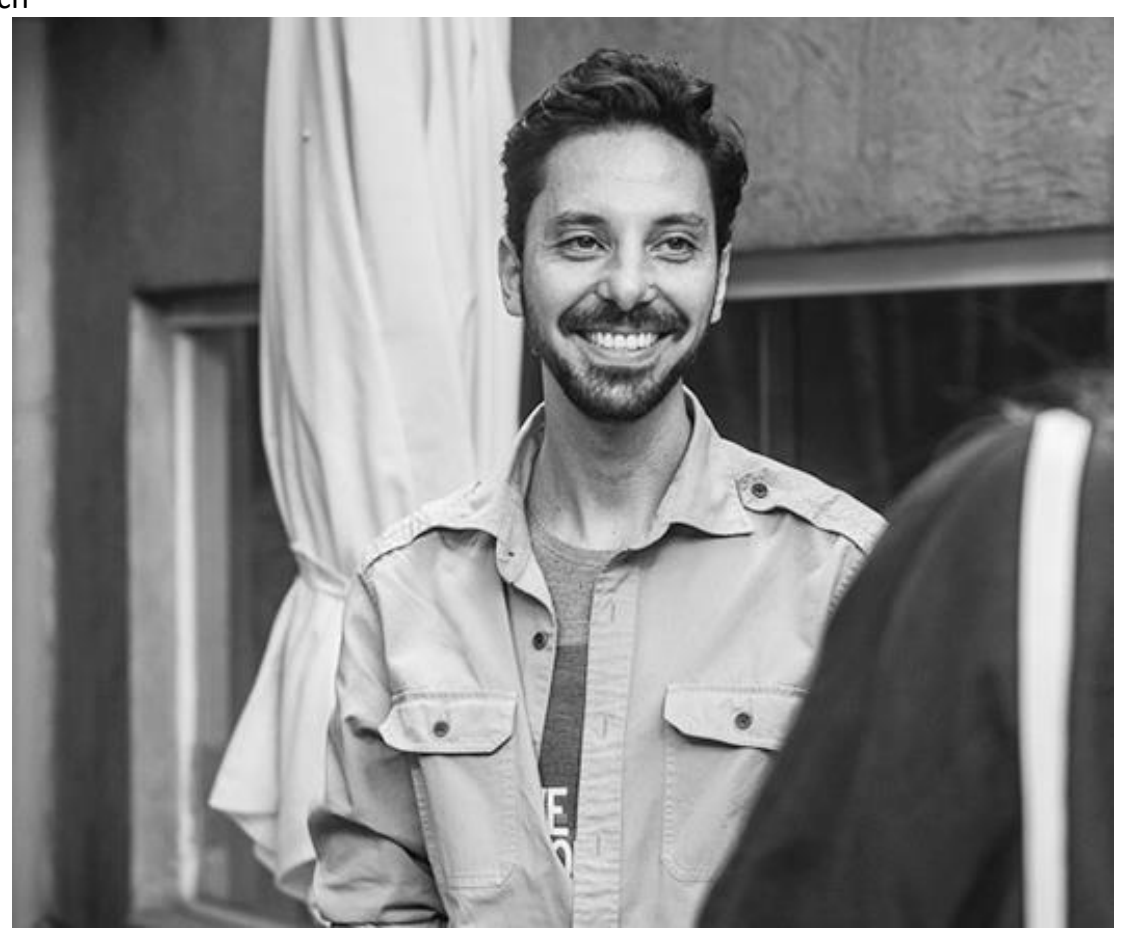

Fonte: Divulgação Instituto Rio Moda, 2015.

Nesta entrevista, o profissional conta sua trajetória e responde perguntas sobre seu trabalho na FARM e algumas metodologias utilizadas pela empresa. Explica como foi desenvolvido o trabalho de identidade da marca e como o seu departamento participa dos processos da empresa.

Carlos também apresenta a importância da comunicação entre os departamentos dentro e fora da empresa, a importância da marca se comunicar e pensar a respeito do que cria e oferece, assim como o papel da marca no mercado e seu relacionamento próximo com suas consumidoras. 


\section{ENTREVISTA}

\section{a. Qual é a sua formação e como começou o seu trabalho com o Branding e a FARM?}

Me formei em publicidade, na FACHA aqui no Rio (de Janeiro), fui diretor de arte em agência de publicidade, fiz freelancer de produção de moda, design gráfico, visual merchandising e comecei a desenvolver trabalhos de branding ainda nessa época.

A minha história na FARM começou de um jeito muito legal, pois eu passei numa loja e vi um projeto de vitrine muito mal executado. Na vitrine havia um cartaz escrito: viva o circo! Nos manequins uma camiseta escrita HIP HOP, então tudo isso junto me fez acreditar que havia uma oportunidade de trabalho.

Marquei uma conversa com a Katia (Barros, proprietária da marca) para apresentar um projeto de vitrine que solucionasse essa confusão, e nessa conversa eu coloquei todos os meus pontos de vista sobre a marca, como eu a enxergava e como eu estava percebendo essa confusão naquele momento. A Katia se identificou com minhas reflexões e me pediu uma proposta de um projeto maior.

Apresentei um projeto de construção de marca com etapas e processos. Fechamos um contrato em 2004 e desde então venho desenvolvendo esse trabalho.

\section{b. Como a identidade da marca FARM foi construída? Foram contratados profissionais} especializados?

A identidade da FARM foi construída pela Katia desde o primeiro dia, ela sempre se preocupou em criar algo próprio. Aqui na FARM trabalhamos como uma house (agência in company), temos os departamentos de criação todos aqui. Isso faz com que essa identidade seja construída por todos nós.

No começo do meu trabalho estruturei algumas etapas para termos um caminho à desbravar, passei 3 meses pesquisando. Depois traduzimos a marca em uma pessoa, definimos atributos indispensáveis e fui estruturando de uma forma profissional os departamentos de criação.

Comecei pelo design e pelos projetos de arquitetura (o escritório da arquiteta Bel Lobo é um exemplo de contratação fora da nossa estrutura interna), junto veio o visual merchandising e depois o Marketing.

Hoje somos quase 300 profissionais atuando na construção dessa identidade. 


\section{c. Qual é a importância da identidade da marca no desenvolvimento do trabalho dentro da} FARM?

Identidade é fundamental. Eu acredito em marcas com expressão criativa e isso é ter uma identidade. Acredito muito na criatividade e por isso o fluxo de construção de uma identidade é bem orgânico. A gente vai experimentando, testando os limites dessa identidade.

Eu respeito muito as coisas que foram criadas no começo da marca e sou um guardião dessa memória, mas quando você realiza um trabalho de construção de marca profundo e longo, é preciso evoluir sempre essa identidade.

d. Como o departamento de branding trabalha? Como é a interação com os outros departamentos?

Já passei por muitos formatos de trabalho aqui, hoje o branding tem o papel de orientação, então executo algumas poucas coisas, aquelas que consideramos muito importantes ainda estão sob o meu comando, mas de uma forma geral a interação com os outros departamentos acontece nas reuniões de alinhamento e nas reuniões de conceituação de projetos.

Sinto que com o crescimento da marca fui ficando num lugar mais estratégico, apesar de não gostar muito dessa palavra. Me vejo num lugar mais de promover reflexões e movimentos, de trazer inovação, tirar a marca da zona de conforto. Mas aqui na FARM o branding hoje não está acima de nenhum departamento de criação, somos todos pares.

\section{e. Quais são os diferenciais da marca e dos produtos da FARM?}

A FARM é uma marca que olha para dentro antes de olhar para fora, isso é o que faz ela existir dessa forma. Acredito que sem isso uma marca não vai muito longe. O que também vem nesse combo é a sensibilidade que temos para criar, emocionar é sempre o objetivo final. Isso começa aqui dentro e reverbera fora.

O produto está dentro desse modo de existir, logo as nossas criações vêm carregadas de histórias, reflexões e criatividade.

\section{f. Quais são os diferenciais da marca e dos produtos da FARM?}

As marcas investem muito dinheiro nessas coisas que as promovem e muito pouco naquilo que realmente importa, que é uma equipe de criação profissional. A verba é sempre pouca então optar por solidez foi uma decisão quase imprescindível para esse trabalho. 
A marca se mantém na vida das clientes através das relações que criamos, sejam em nossas lojas ou nas redes sociais.

Figura 2 - Imagem de coleção do website da marca

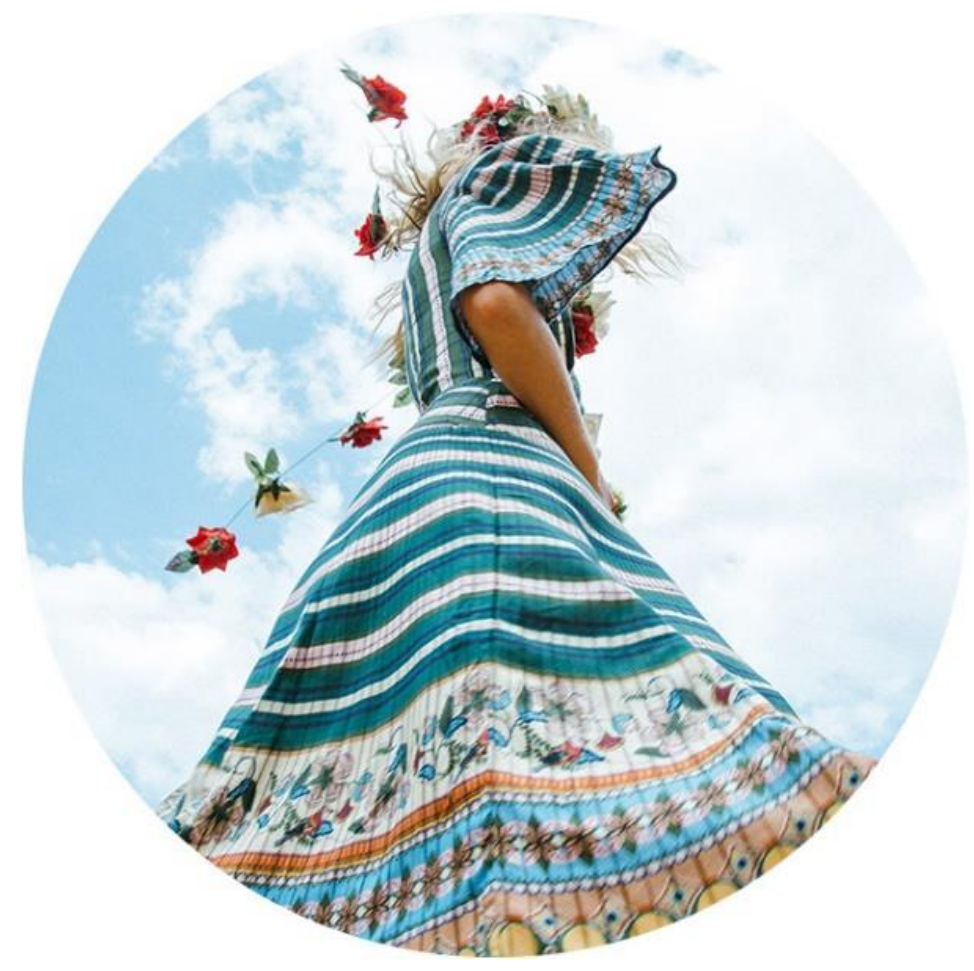

Fonte: Divulgação FARM RIO, 2016.

g. Como é o start de uma coleção da FARM? Como os departamentos se envolvem na criação de uma nova coleção?

A gente tem um núcleo de conceito de coleção que é multidisciplinar. Os departamentos de criação contribuem com aquilo que tem de melhor nas reuniões. Vamos editando as melhores ideias, aquelas que emocionam e chegamos assim no $X$ da questão. Naquilo que vamos comunicar para o mercado.

\section{h. De que forma o departamento de branding participa desse processo?}

O Branding participa trazendo sempre ideias que geram movimento para a marca. Fazendo essa ponte com algo que criamos lá atrás e que de alguma forma pode ser revisitado.... A gente também faz a apresentação de conceito para o departamento de estilo. 


\section{i. A FARM acompanha o estilo de vida das suas clientes? Como isso é feito?}

Sim, temos que. Essa conexão com o comportamento é muito importante para uma marca contemporânea. Nós observarmos, e observar as pessoas é algo muito presente no nosso dia-a-dia.

j. Isso substitui a pesquisa de tendências no suprimento de insights para novos produtos?

Tudo acrescenta. Acredito que todas as tendências que existem hoje refletem o momento. O que penso ser mais legal do que seguir tendências é você acreditar que é um agente transformador.

Quando a marca se coloca nesse lugar acabamos promovendo movimentos que talvez aconteçam antes de virar tendência, e é esse lugar que gosto de estar.

k. A FARM pretende se tornar uma marca internacional. Como isso impacta a identidade da marca?

Sim. Impacta do ponto de vista de estarmos abertos para esse aprendizado. De entendermos como essa nova relação vai se estabelecer.

O mundo está aberto para a criatividade, para a verdade, então assim tudo vai surgindo sem grandes planos de dominar o mundo.

\section{REFERÊNCIAS}

FARM RIO. 27 jun. 2016. 1 fotografia. Disponível em https://adoro.farmrio.com.br/de-tudo-umpouco/vem-ai-sotaque-brasil/. Acesso em: 12 jul. 2019.

INSTITUTO RIO MODA. Carlos Mach. Rio de Janeiro, 24 nov. 2015. Facebook: institutoriomoda. Disponível em:

https://www.facebook.com/institutoriomoda/photos/a.209468699064284/1090396804304798/?t ype=3\&theater. Acesso em: 12 jul. 2019. 